\title{
Statistical optimization of amorphous iron phosphate: inorganic sol-gel synthesis-sodium potential insertion
}

\author{
Fz. Maarouf ${ }^{1}$, S. Saoiabi ${ }^{1}$, K. Azzaoui2 ${ }^{2}$, C. Chrika ${ }^{1}$, H. Khalil' ${ }^{1}$ S. Elkaouni ${ }^{1}$, S. Lhimr ${ }^{1}$, O. Boubker ${ }^{3,5}$, \\ B. Hammouti ${ }^{2}$ and S. Jodeh ${ }^{4^{*}}$ (D)
}

\begin{abstract}
Iron phosphate, $\mathrm{Fe}_{2}\left(\mathrm{HPO}_{4}\right)_{3}{ }^{*} 4 \mathrm{H}_{2} \mathrm{O}$, is synthesized at ambient temperature, using the inorganic sol-gel method coupled to the microwave route. The experimental conditions for the gelling of Fe (III)- $\mathrm{H}_{3} \mathrm{PO}_{4}$ system are previously defined. Potentiometric Time Titration (PTT) and Potentiometric Mass Titration (PMT) investigate the acid-base surface chemistry of obtained phosphate. Variations of surface charge with the contact time, Q a function of T, are examined for time contact varying in the range $0-72 \mathrm{~h}$. The mass suspensions used for this purpose are $0.75,1.25$ and $2.5 \mathrm{~g} \mathrm{~L}^{-1}$. The point of zero charge (PZC) and isoelectric point (IEP) are defined using the derivative method examining the variations $\frac{\mathrm{dpH}}{\mathrm{dt}}=f(\mathrm{pH})$, at lower contact time. A shift is observed for PZC and IEP towards low values that are found to be $2.2 \pm 0.2$ and $1.8 \pm 0.1$, respectively. In acidic conditions, the surface charge behavior of synthesized phosphate is dominated by $>\mathrm{POH}$ group which $\mathrm{pK}_{\mathrm{a}}=2.45 \pm 0.15$. Q against $\mathrm{T}$ titration method is performed for synthesized $\mathrm{Fe}_{2}\left(\mathrm{HPO}_{4}\right)_{3}{ }^{*} 4 \mathrm{H}_{2} \mathrm{O}$ in NaCl electrolytes. The maximal surface charge $(\mathrm{Q})$ is achieved at the low solid suspension. Hence, for $m=0.75 \mathrm{~g} \mathrm{~L}^{-1}$, Q value of 50 coulombs is carried at $\mu=0.1$ and $\mathrm{pH}$ around 12, while charge value around 22 coulombs is reached in the $\mathrm{pH}$ range: $3-10$. The effect of activation time, $\mathrm{Q}$ and $\mathrm{pH}$ on sodium insertion in iron phosphate, were fully evaluated. To determine the optimal conditions of the studied process, mathematical models are used develop response surfaces in order to characterize the most significant sodium interactions according to the variation of the $\mathrm{pH}, \mathrm{Q}$, the contact time and the contents of the synthesized material.
\end{abstract}

Keywords: Amorphous, Iron phosphate, Inorganic sol-gel, IEP, PZC, Surface property, Surface charge, Statistical optimization, Sodium insertion

\section{Introduction}

The emerging attention to environmental pollution and energy consumption and the rapid promotion and innovation of electronic devices has created a surge in demand for more efficient and clean energy storage and conversion devices. To avoid the use of rare metals,

\footnotetext{
*Correspondence: k.azzaoui@yahoo.com; sjodeh@hotmail.com ${ }^{2}$ LCAE-URAC18, COST, Department of Chemistry, Faculty of Sciences, Mohamed 1st University, P.O. Box 717, 60000 Oujda, Morocco

${ }^{4}$ Department of Chemistry, College of Science, An-Najah National University, Nablus, Palestine

Full list of author information is available at the end of the article
}

extensive research is undertaken to develop a second generation of batteries, known as post-lithium ion secondary batteries. Sodium and potassium are among the elements proposed as charge carriers in these batteries. The large ionic dimension of $\mathrm{Na}^{+}(1.02 \AA)$ compared to $\mathrm{Li}^{+}(0.76 \AA)$ is coupled to slow diffusion, interphase formation and phase stability $[1,2]$. The storage capacities in crystalline hosts are limited by the low ion migration associated to the stoichiometric restraint of ion insertion. Compared to lithium insertion, the incorporation of $\mathrm{Na}^{+}$and $\mathrm{K}^{+}$ions is considered as big challenge, in this material. The main diffusion mechanism involving

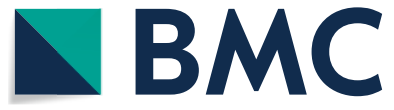

C The Author(s) 2021. This article is licensed under a Creative Commons Attribution 4.0 International License, which permits use, sharing, adaptation, distribution and reproduction in any medium or format, as long as you give appropriate credit to the original author(s) and the source, provide a link to the Creative Commons licence, and indicate if changes were made. The images or other third party material in this article are included in the article's Creative Commons licence, unless indicated otherwise in a credit line to the material. If material is not included in the article's Creative Commons licence and your intended use is not permitted by statutory regulation or exceeds the permitted use, you will need to obtain permission directly from the copyright holder. To view a copy of this licence, visit http://creativeco mmons.org/licenses/by/4.0/. The Creative Commons Public Domain Dedication waiver (http://creativecommons.org/publicdomain/ zero/1.0/) applies to the data made available in this article, unless otherwise stated in a credit line to the data. 
a single step is performed in one-dimensional channels. To overcome this phenomenon requires appropriate electrode active materials [3, 4]. Thus, open framework materials such as phosphates have emerged as host matrices for these alkaline elements intercalation/deintercalation [5]. The amorphous products with disordered structures may electrochemically store and release these voluminous alkali ions. For this purpose, amorphous iron phosphates which are chemically stable are considerably explored for use in sodium ion batteries. So, $\mathrm{NaFePO}_{4}$ is a promising cathode material for no-lithium batteries. Due to the high activation barriers, $\mathrm{Na}^{+}$diffusion is of lower extent in crystalline Fe-phosphates. As a result, $\mathrm{Na}^{+}$extraction from these electrode materials requires an activation energy lowering that is achieved through amorphization of phosphates and results in an increase of $\mathrm{Na}$ diffusion [6]. Little is known about this diffusion process which is governing the phase stability of $\mathrm{Na}_{x} \mathrm{FePO}_{4}(\mathrm{x}<1)$ during sodiation-desodiation phenomenon. The insertion chemistry of lithium and sodium carried out in $\mathrm{FePO}_{4}$ are, therefore, considerably different [4]. Hence, the development of the post-lithium batteries requires to understand several processes of sodium and potassium ion chemistry and surface chemistry such as kinetics and insertion mechanisms of $\mathrm{Na}(\mathrm{K}) \mathrm{FePO}_{4}$ electrodes [7].

One can note that although the amorphous state of $\mathrm{FePO}_{4}$ is suitable for electrochemical activity, a presodiation (or potassiumation) step is crucial and can be performed by chemical or electrochemical ways. The surface properties and the electrified hydrated interfaces play a main role in interaction of phosphate aggregates with various aqueous particles. The surface suspensions charge occurs from proton transfer during ionization (protonation and deprotonation) of the surface hydroxyl groups, $>\mathrm{S}-\mathrm{OH}$, which results in $>\mathrm{SOH}_{2}{ }^{+}$or $>\mathrm{SO}^{-}$species. Generally it is admitted that ionization reactions are controlled, essentially, by the $\mathrm{pH}$ and ionic strength of dispersion medium.

It is shown previously that the increase in mass of some metal suspensions is associated with an increase in point of zero charges (PZS) value. This increase is suggested to be a result of oxide surface hydration. The value of the isoelectric point (IEP) is dependent on initial $\mathrm{pH}$ and decreases as this $\mathrm{pH}$ and electrolyte salt $\left(\mathrm{KNO}_{3}\right)$ concentration increase [8]. The proton affinity of surface groups is then essential in $\mathrm{H}^{+} / \mathrm{OH}^{-}$sorption exchange processes and it determines the charging and the binding behavior of sorbents [9]. In general, the point of zero charges is identified as the initial $\mathrm{pH}$ corresponding to minimal variation and associated with
$\Delta \mathrm{pH} \sim 0$. Also, it is assumed that surface equilibrium is reached after a contact time of about $24 \mathrm{~h}$ [10].

In this study, acid iron phosphates are synthesized following a sol-gel route associated to a microwave irradiation $(800 \mathrm{w})$ for an about $15 \mathrm{~s}$. The synthesis was undertaken within the $\mathrm{pH}$ formation range of monohydrogen phosphate. The surface chemistry of the soobtained particles was studied to understand the Fe/P ratio effects. To achieve this purpose, two potentiometric techniques were carried out using Potentiometric Time Titration (PTT) and Potentiometric Mass Titration (PMT). The suspensions used, for this purpose, were of $0.75,1.25$ and $2.5 \mathrm{~g} / \mathrm{L}$. These suspensions were aging for different times (T) up to $72 \mathrm{~h}$.

\section{Materials and methods}

All chemicals are of reagent quality (Sigma-Aldrich) and used without purification. Phosphoric acid $(0.1 \mathrm{M})$ and iron (III) nitrate $(0.1 \mathrm{M})$ were used as the starting materials. The ionic strength, $\mu$, is adjusted to value of 0.001 , 0.01 and 0.1 with $\mathrm{NaCl}$ as electrolyte salts.

The batch equilibration technique was applied to determine the Point of Zero Charge (PZC). To achieve this purpose, titrations of $\mathrm{HNO}_{3}(0.05 \mathrm{M})$-iron phosphate systems were carried out at room temperature with $\mathrm{KOH}(0.05 \mathrm{M})$. Surface charge variations Q against T, were examined for $\mathrm{FePO}_{4}$ suspensions of 0.75, 1.25 and $2.5 \mathrm{~g} / \mathrm{L}$.

\section{Synthesis of iron (III) phosphate}

Iron (III) phosphate was synthesized by a modified inorganic sol-gel method [11]. A solution of a Fe/P molar ratio of 1:1.5 is gellified by a microwave irradiation and the resulting gel is oven-dried at $50^{\circ} \mathrm{C}$ for about $48 \mathrm{~h}$. The xerogels are washed with distilled water and ethanol to obtain the final phosphates. All the phosphate samples were then characterized using X-ray diffraction analysis and FTIR spectroscopy. The results show that the amorphous phase was $\mathrm{Fe}_{2}\left(\mathrm{HPO}_{4}\right)_{3}{ }^{*} \mathrm{xH}_{2} \mathrm{O}$.

\section{Experimental instruments}

All the phosphate samples were then characterized using X-ray diffraction analysis and FTIR spectroscopy. The $\mathrm{X}$-ray diffraction (XRD) spectra were performed using an X-ray powder diffractometer (LabxXRD-6100 Shimadzu) with an acquisition rate of 0.05 to $25^{\circ} /$ min $(\theta)$ ). The recording of our IR spectra in the $4000-250 \mathrm{~cm}^{-1}$ range is carried out using an IR spectrometer of the PERKIN ELMER 577 type or using an IR spectrometer 1600 FTIR, the samples studied are intimately crushed with $\mathrm{KBr}$ and shaped in the form of pellets. These techniques are used in conjunction with thermal analysis (DTA) and thermogravimetric analysis (TGA) to follow the thermal 


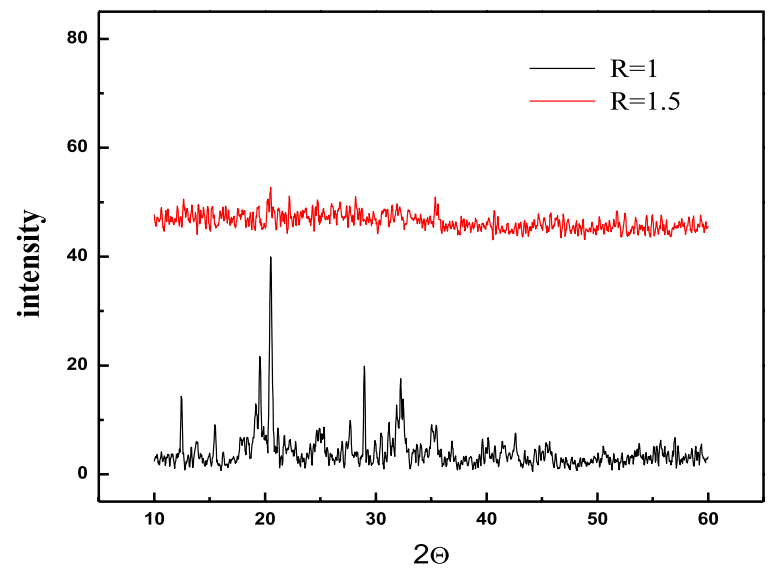

Fig. 1 Diffractograms of xerogel obtained in $\mathrm{Fe}(\mathrm{III})-\mathrm{H}_{3} \mathrm{PO}_{4}$ system with $\mathrm{R}=\mathrm{P} / \mathrm{Fe}=1.5$ and $\mathrm{R}=\mathrm{P} / \mathrm{Fe}=1$

evolution of these Xerogel phosphates, Thermogravimetric (TGA) and differential thermal analysis (DTA) (Labsys Evo1F Setaram). Morphological surface features were examined by applying Jeol JSM-IT100 InTouchScope ${ }^{\text {TM }}$ Scanning Electron Microscope (SEM) connected to a microanalyzer EDS [12].

\section{Results and discussions \\ $X$ ray diffraction}

Figure $1(R=1)$ shows the XRD spectrogram of iron phosphate. It can be seen that all three types of materials have sharp characteristic diffraction peak and the peak positions are very similar to each other. Compare with the JCPDS01-081-1173 standard spectrum diagram.

While at $(\mathrm{R}=1.5)$ shows XRD patterns of synthesized iron phosphate powders. As shown, XRD patterns of as-synthesized phosphate shows no intense broad peaks indicating amorphous iron phosphate.

\section{Infrared spectroscopy}

The FTIR spectrum of synthesized iron phosphate is shown in Fig. 2. This FTIR spectrum is normalized to the intensity of the (PO) (P-O stretching band) at $1044 \mathrm{~cm}^{-1}$.

The functional groups of iron phosphate and precursor material are presented in Fig. 2. The presence of low intensity bands in the $3600-2700 \mathrm{~cm}^{-1}$ is characteristic of the hydroxyl-stretching vibrations of water, and acid phosphate. The IR band observed at $1640 \mathrm{~cm}^{-1}$ is associated with the strong hydrogen bonding of the water molecules to the phosphate anions. The large intense band at 1044 and the weak band at $900 \mathrm{~cm}^{-1}$ are associated with $\mathrm{P}-\mathrm{OH}$ stretching vibrations of $\mathrm{HPO}_{4}{ }^{2-}[13-16]$

The precursor sample also had symmetrical stretching vibration peak of $\mathrm{P}-\mathrm{O}$ bond at $1428.66 \mathrm{~cm}^{-1}$,

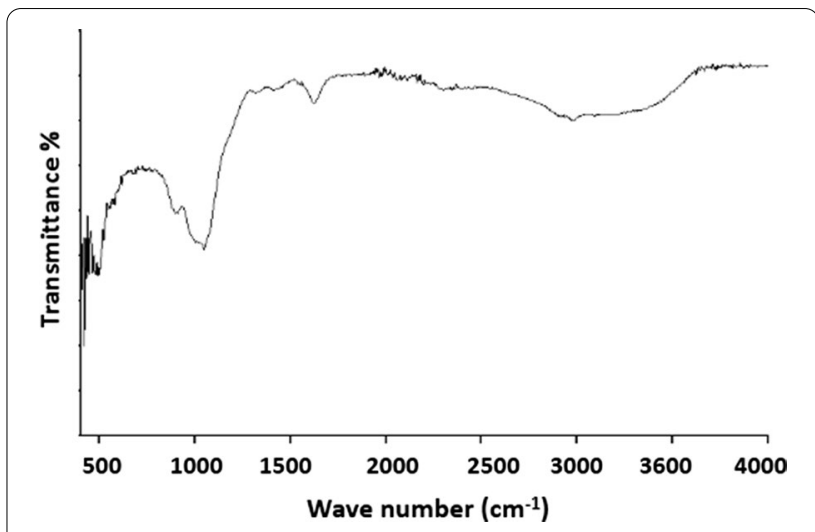

Fig.2 FTIR spectrum of iron phosphate with a ratio $\mathrm{P} / \mathrm{Fe}=1.5$

symmetrical stretching vibration peak of $\mathrm{P}-\mathrm{O}$ bond at 526.13 and $1047.63 \mathrm{~cm}^{-1}$.

\section{DTA-TGA spectrum of the iron phosphate}

Thermal study of iron phosphates is carried out using thermogravimetric analysis (TGA) and differential analysis (DTA) from room temperature to about $900{ }^{\circ} \mathrm{C}$. Obtained results are shown in Fig. 3.

The DTA curve indicates a sharp endothermic peaks appearing at 225,370 and $540{ }^{\circ} \mathrm{C}$. The first peak associated with weight loss of 15.1 wt.\% on the TG curve is related to a quick dehydration of $\mathrm{Fe}_{2}\left(\mathrm{HPO}_{4}\right)_{3} * 4 \mathrm{H}_{2} \mathrm{O}$. The second peak with low weight loss is due to initial decomposition involving dehydratation of phosphate matrix. The third peak represents the essential decomposition that is corresponding to the phosphate condensation in which a hydroxyl polymerized chain is obtained without structure destruction. Occurring polymerization process is associated to weight loss of about $1.4 \mathrm{wt} . \%$ $[14,18]$. The obvious exothermic peak at $605{ }^{\circ} \mathrm{C}$ together with three tiny peaks at $762{ }^{\circ} \mathrm{C}, 795^{\circ} \mathrm{C}$, and endothermic peak at $815^{\circ} \mathrm{C}$, is attributed to the phase transformation. As shown previously, the tiny peaks are associated with three-step structural transformation of the iron phosphate framework $[17,18]$.

\section{Surface morphology of synthesized phosphate}

The surface morphology of synthesized phosphate samples is studied by the scanning electron microscopy (SEM) technique. Figure 4 shows the SEM micrograph and its energy dispersive X-ray spectroscopy (EDX) image obtained with $1000 \times$ magnification and a scale bar of $20 \mu \mathrm{m}$.

It is shown that the phosphate surface is porous and composed of $\mathrm{Fe}, \mathrm{P}$, and $\mathrm{O}$, confirming the purity of phosphate materials. SEM studies show that agglomerates are plate and spherical in structure. The 


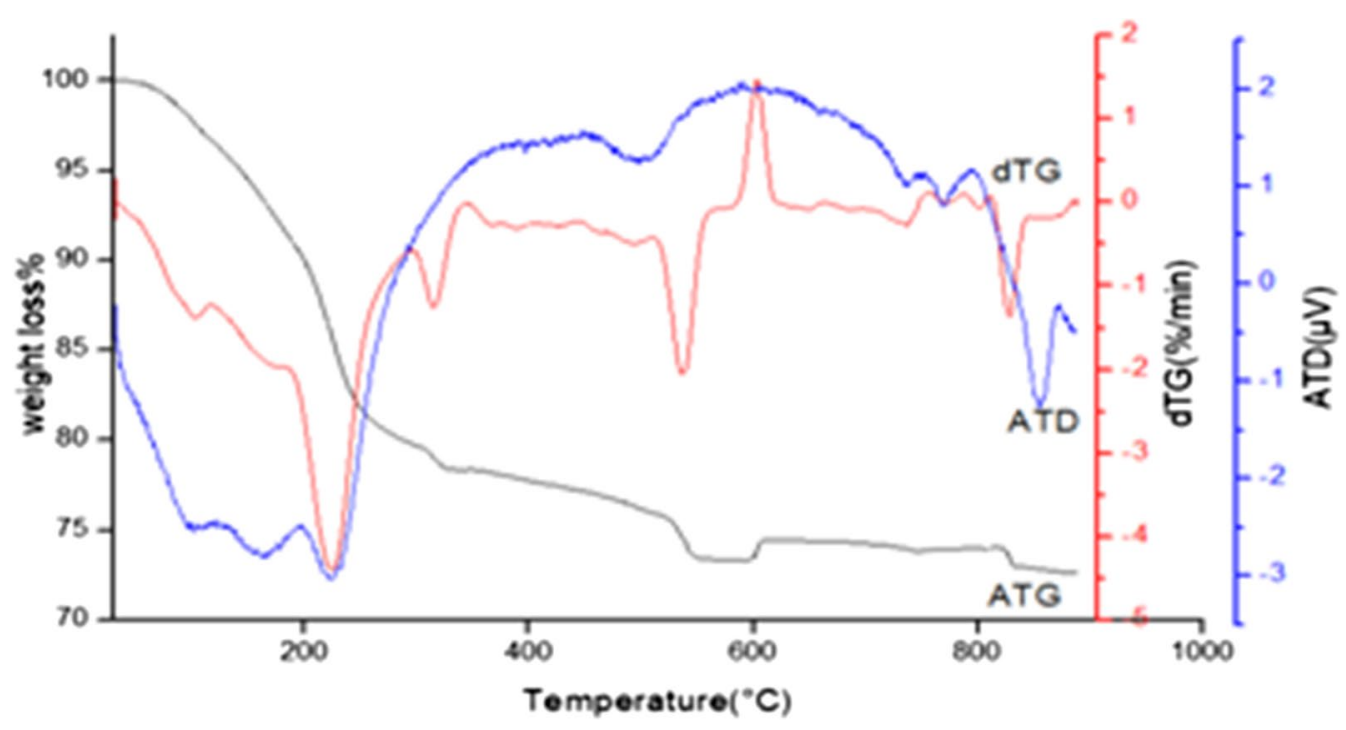

Fig. 3 DTA-TGA of iron phosphate amorphous synthesized phosphate at $\mathrm{P} / \mathrm{Fe}=1.5$

spherical aggregates are formed by cluster of small particles that are characterized by both low density and contact area. This result in higher specific surface is associated to greater porosity [19]. Consequently, spherical phosphates are more suitable for their electrochemical performance because of the Li ion diffusion [20].

\section{Point of zero charge}

In the present study, the point of zero charge (PZS) and isoelectric point (IEP) for ferric phosphate material are determined by kinetic-potentiometric method. The proton affinity which is of direct concern in proton exchange, is measured by $\mathrm{pH}$ change of phosphate suspensions. After agitation and settling time $(\mathrm{T})$ varying from 30 to $150 \mathrm{~min}$, the $\mathrm{pH}$ is measured for suspension of $0.75,1.25$ and $2.5 \mathrm{~g} / \mathrm{L}$. The initial $\mathrm{pH}$ is adjusted between 2 and 13, and the variations $\mathrm{pH}$ in function of $\mathrm{T}$ are best fitted $\left(R^{2}>99 \%\right)$ by the cubic equations. A first derivative method is used to graph $\frac{\mathrm{dpH}}{\mathrm{d} T}$ in function of $\mathrm{pH}$ shown in Fig. 5.

From obtained results, the surface reactions involve principally, proton release. The $\mathrm{OH}^{-}$liberation or $\mathrm{H}^{+}$ uptake process is occurring at low suspension in a narrow $\mathrm{pH}$ range. It is important to note, as indicated previously, that the release of $\mathrm{H}^{+}$to the solution results in deprotonated and negatively charged suspension [21].

As discussed previously, the $\mathrm{pH}$ response pattern is dependent on specific mass suspension. Thus, the rate of $\mathrm{pH}$ change observed at 1.25 and $2.5 \mathrm{~g} / \mathrm{L}$ slurry is associated to proton liberation and results in $\mathrm{pH}$ decrease in the whole $\mathrm{pH}$ range. Vanishes of $\frac{\mathrm{dpH}}{\mathrm{d} T}$ with a broad maximum are occurring around $\mathrm{pH}=4.0$ and just correspond to zero charge, since no opposite in sign is observed for $\mathrm{dpH}$. For $0.75 \mathrm{~g} / \mathrm{L}$ suspension, rapid $\mathrm{pH}$ growth in the $\mathrm{pH}$ range $4-6$ is crossing $\mathrm{x}$-axis at the point of zero charge which value is $4.3 \pm 0.1$. A scarcity of literature data concerns the point of zero charge of iron(III) (hydrogen) phosphates, but it is important to note that obtained PZC value is higher, compared to that of $\mathrm{Fe}_{3}\left(\mathrm{PO}_{4}\right)_{2}$, and $\mathrm{Cr}(\mathrm{III})$ and $\mathrm{Al}(\mathrm{III})$ phosphates which values are 3.3 , and 2.6 , respectively. For rare earth phosphates, the IEP and PZC values are found to occur in the $\mathrm{pH}$ range of 6.0 to 7.2 [22-24]. The zero rate change recorded for $0.75 \mathrm{~g} / \mathrm{L}$, at $\mathrm{pH}$ varying from 6 to 10 means that the net total charge exchange is equal to 0 . Consequently, proton release is controlled mainly by mass suspension and diminishes as this mass increases. Furthermore, obtained results show that $\mathrm{IEP}=\mathrm{PZC}=4.3 \pm 0.1$ suggesting no specific sorption of ions other than protons [25].

The zero surface charges occurring around PZC are independent of initial $\mathrm{pH}$ and are presenting no shift with contact time. The results also demonstrate that $\frac{\mathrm{dpH}}{\mathrm{d} T}$ in function of $\mathrm{pH}$ curves are reliant to concentration of iron suspensions, and are resulting in convergence or divergence plots at pHs close to PZC [26, 27]. As found, $\mathrm{PZC}$ is independent on time contact and is corresponding to an extremum of $\mathrm{pH}$ against $\mathrm{T}$ variations. As discussed below, the relatively high point of zero charge value indicates the predominance of positively charged surface groups corresponding, in explored conditions, to $>\mathrm{FeOH}[25]$. 

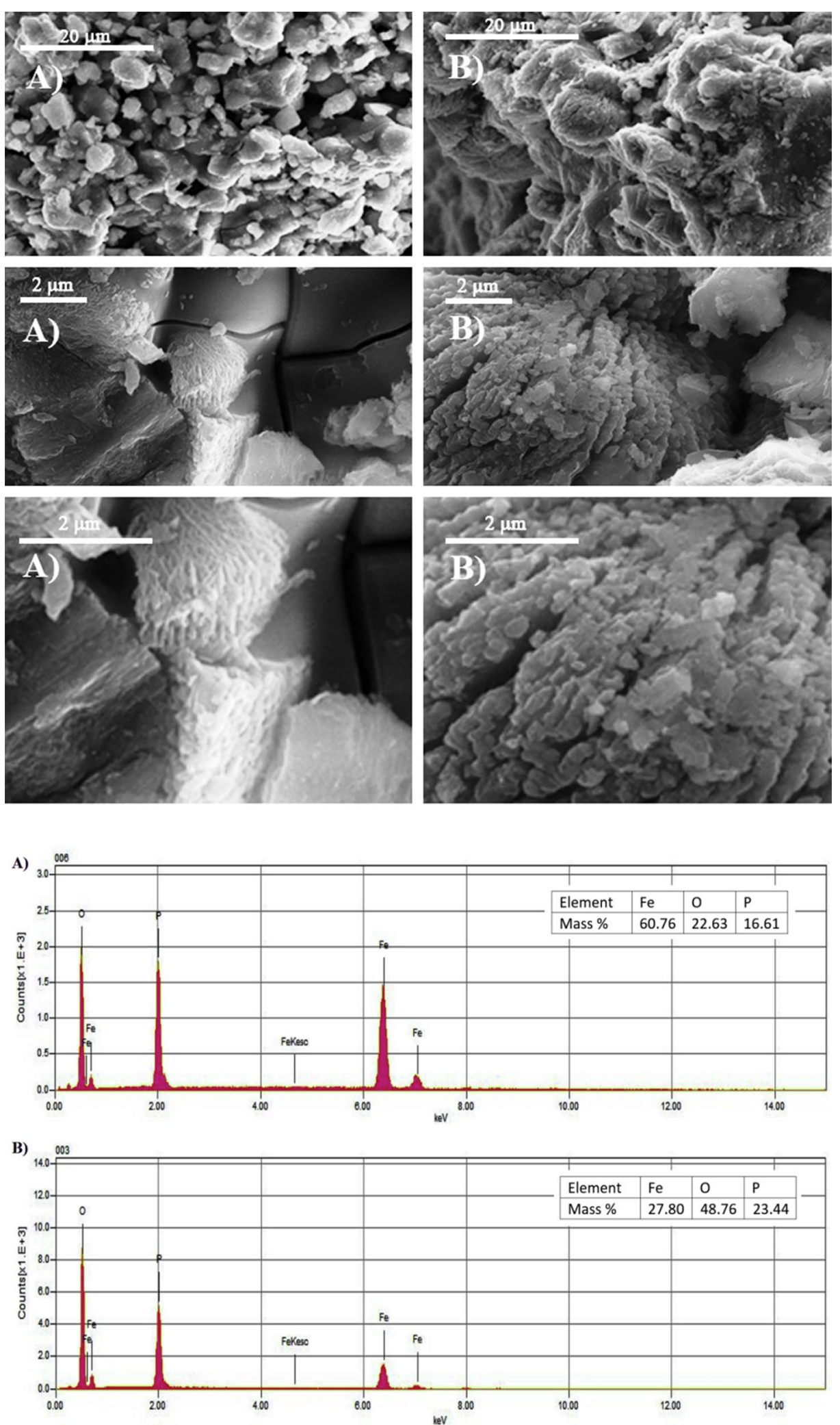

Fig. 4 A SEM images and EDS results of as-prepared iron phosphate with Fe/P =1.48. B SEM images and EDS results of as-prepared iron phosphate with $\mathrm{P} / \mathrm{Fe}=1.66$ 

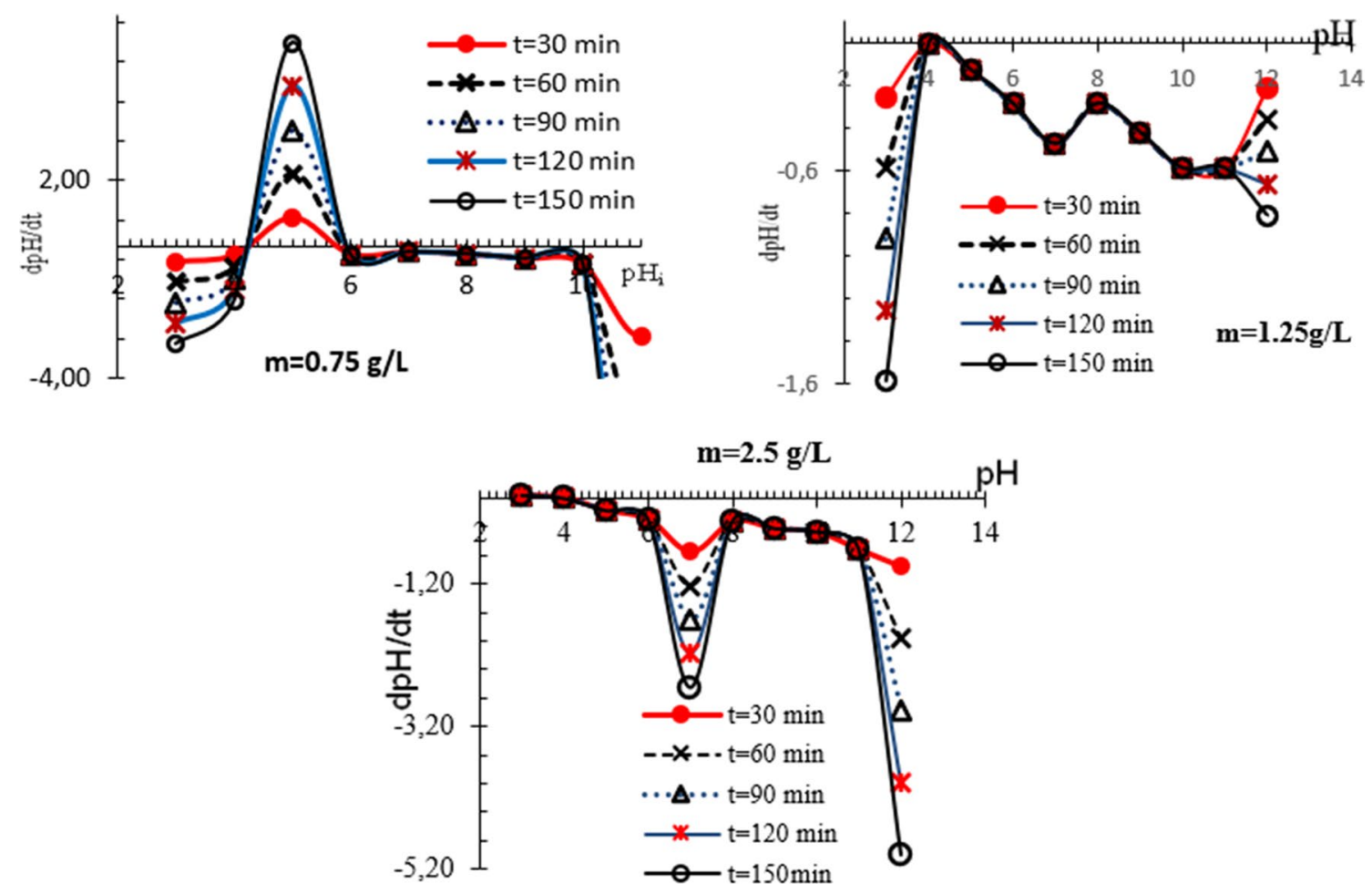

Fig. 5 Variations of $\frac{d p H}{d T}$ in function of $\mathrm{pH}$ obtained for iron phosphate at $\mathrm{m}=0.75,1.25$ and $2.5 \mathrm{~g} / \mathrm{L}$

\section{Potentiometric acid-base titration}

The $\mathrm{pH}$-dependent surface charge (Q) of iron (III) monohydrogen phosphate is studied by acid-base titration at $\mu$ value of $0.001,0.01$ and $0.1 \mathrm{M}$. Equilibrium titration is performed at ambient temperature for contact time $(\mathrm{T})$ varying between 0.5 and $72 \mathrm{~h}$.

The acid-base behavior of the phosphate surface is attributed to phosphohydrols $(\overline{>\mathrm{POH}})$ and ferrihydrols $(\overline{\mathrm{FeOH}})$. The surface suspension acquires an electrostatic charge $\mathrm{Q}$, owing to protonation/deprotonation processes that are well described as reactions of amphoteric ion exchanger materials $(\overline{>\mathrm{SOH}})$ :

$$
\begin{aligned}
& \overline{>\mathrm{SOH}}+\mathrm{H}^{+} \leftrightarrow \overline{>\mathrm{S}\left(\mathrm{OH}_{2}\right)^{+}}, \quad \mathrm{K}_{\mathrm{eq}}^{+} \\
& \overline{>\mathrm{SOH}} \leftrightarrow \overline{>\mathrm{SO}^{-}}+\mathrm{H}^{+}, \mathrm{K}_{\mathrm{eq}}^{-}
\end{aligned}
$$

$\mathrm{K}_{\mathrm{eq}}{ }^{+}$and $\mathrm{K}_{\mathrm{eq}}{ }^{-}$respectively denote the surface stability constants, while the on the lined species belong to the solid phase. The pKa of $\overline{>\mathrm{POH}}$ and $\overline{>\mathrm{FeOH}}$ are respectively 1.44 , and $4.66[28,29]$.

Generally, it is found that the particle surfaces of metal oxides are saturated and no more varying for $\mathrm{pH} \leq 3$ and $\mathrm{pH} \geq 11$ [30].

The synthesized iron phosphate is suspended in $25 \mathrm{ml}$ of $0.05 \mathrm{M} \mathrm{HNO}_{3}$ and titrated with a standard solution of $0.05 \mathrm{M} \mathrm{NaOH}$. The surface charge (Q) is determined using potentiometric techniques of time titration (PTT) and mass titration (PMT). In these methods, phosphate dispersions with different weights of $0.75,1.25$ and $2.5 \mathrm{~g} / \mathrm{L}$ are titrated at contact time $(\mathrm{T})$ that has varied between 0.5 and $72 \mathrm{~h}$. A blank solution without iron phosphate is also titrated in these conditions.

\section{Surface charge of iron phosphate}

The surface charge, Q, of phosphate suspension is obtained from curves titration obtained at given $\mathrm{m}, \mathrm{pH}$ and $\mathrm{T}$. The proton-reactive surface functional groups which are the main active elements in adsorption processes, are contributing also to acid-base properties of sorbent suspension. These properties which are the principal of PTT and PMT methods are based on $\mathrm{pH}$ difference between blank and phosphate suspension, for given neutralization volume of $\mathrm{NaOH}$.

The charge $\mathrm{Q}$ is determined according to:

$$
Q=\frac{F C \Delta V}{m}(\text { Coulomb } / \mathrm{g})
$$

The variations $\mathrm{Q}$ in function of $\mathrm{pH}$ allow determining both the point of zero charge (PZC) and isoelectric point (IEP). 
$\mathrm{F}$ is the Faraday constant, $\mathrm{C}$ is the concentration of acid and base used in a titration, $\Delta \mathrm{V}$ is the difference in the volume of base used to reach the same $\mathrm{pH}$ in dispersion and blank solution, and $\mathrm{m}(\mathrm{g} / \mathrm{L})$ is the suspension concentration of the solid particles.

\section{$\mathrm{pH}$-dependent surface charge in $\mathrm{NaCl}$ ectrolyte}

To study the $\mathrm{pH}$-dependence of surface charge of phosphate particles, the $Q$ value is determined at various $\mu$ and contact time $(\mathrm{T})$. Figure 6 shows $\mathrm{Q}$ in function of $\mathrm{T}$ variations achieved at $0.001 \mathrm{M} \mathrm{NaCl}$ for phosphate suspensions $(\mathrm{m})$ of $0.75,2.15$ and $2.5 \mathrm{~g} \mathrm{~L}^{-1}$.

During the suspension process, the iron phosphate surface develops a charge consequent to the $\mathrm{Na}^{+}$or $\mathrm{Cl}^{-}$insertion. This charge is contact time dependent while the permanent charged sites are involved in $\mathrm{H}^{+}$ $\left(\mathrm{OH}^{-}\right)$-exchange reaction. The negative charge on phosphate particles associated to $0.75 \mathrm{~g} \mathrm{~L}^{-1}$ is prevailing over the whole $\mathrm{pH}$ range. $\mathrm{Q}$ value ranging from -27 to -31 Coulombs is achieved in the $\mathrm{pH}$ range: 4.4-11.6, while a charge around -18.5 coulombs is obtained in this condition at $\mathrm{m}=1.25 \mathrm{~g} \mathrm{~L}^{-1}$. The positive charge obtained in the other explored conditions is no significant.

The absence of common intersection point of $Q$ in function of $\mathrm{pH}$ curves shows that the characteristic $\mathrm{pH}$ of isoelectric point is dependent on contact time and mass suspension. The common intersection point of surface-charging curves observed at $\mathrm{pH}$ value of 1.8 is corresponding to IEP. The point of zero charge which corresponds to cross point of these variations is observed at $\mathrm{pH}$ around 2.4 .

The following curves in Figs. 7 and 8 show the variations $\mathrm{Q}$ in function of $\mathrm{pH}$ obtained for iron phosphate at 0.01 and $0.1 \mathrm{M} \mathrm{NaCl}$.

As shown from $0.75 \mathrm{~g} \mathrm{~L}^{-1}$ suspension results, the IEP and the PZC are dependent on contact time and are respectively 1.8 and 2.4 .

Figure 8 represents $\mathrm{Q}$ as a function of $\mathrm{pH}$ for different contact time.

Obtained results show that, as ionic strength increases, phosphate particles are no or less negatively charged. The maximum $Q$ value is achieved at $\mathrm{m}=0.75$ $\mathrm{g} \mathrm{L}^{-1}$ and $\mu=0.1$ for $\mathrm{pH}$ around 12 . In this optimal $\mathrm{pH}$ conditions, the surface charge starts to become independent of contact time and increases rapidly to reach 50 coulombs. The similarity of $\mathrm{Q}$ against $\mathrm{T}$ curves with a positive plateau between $\mathrm{pH} 3$ and 10.4, indicates that the increase in $\mathrm{Q}$ is essentially due to $\mathrm{Na}^{+}$ inclusion. A negative IEP is shown at $\mathrm{pH}$ around 1.8, while PZC value of 2.2 is achieved in these conditions. Moreover, at $\mathrm{pH}$ higher than $\mathrm{PZC}$, a rapid shift of the surface charge toward positive values is occurred. It is
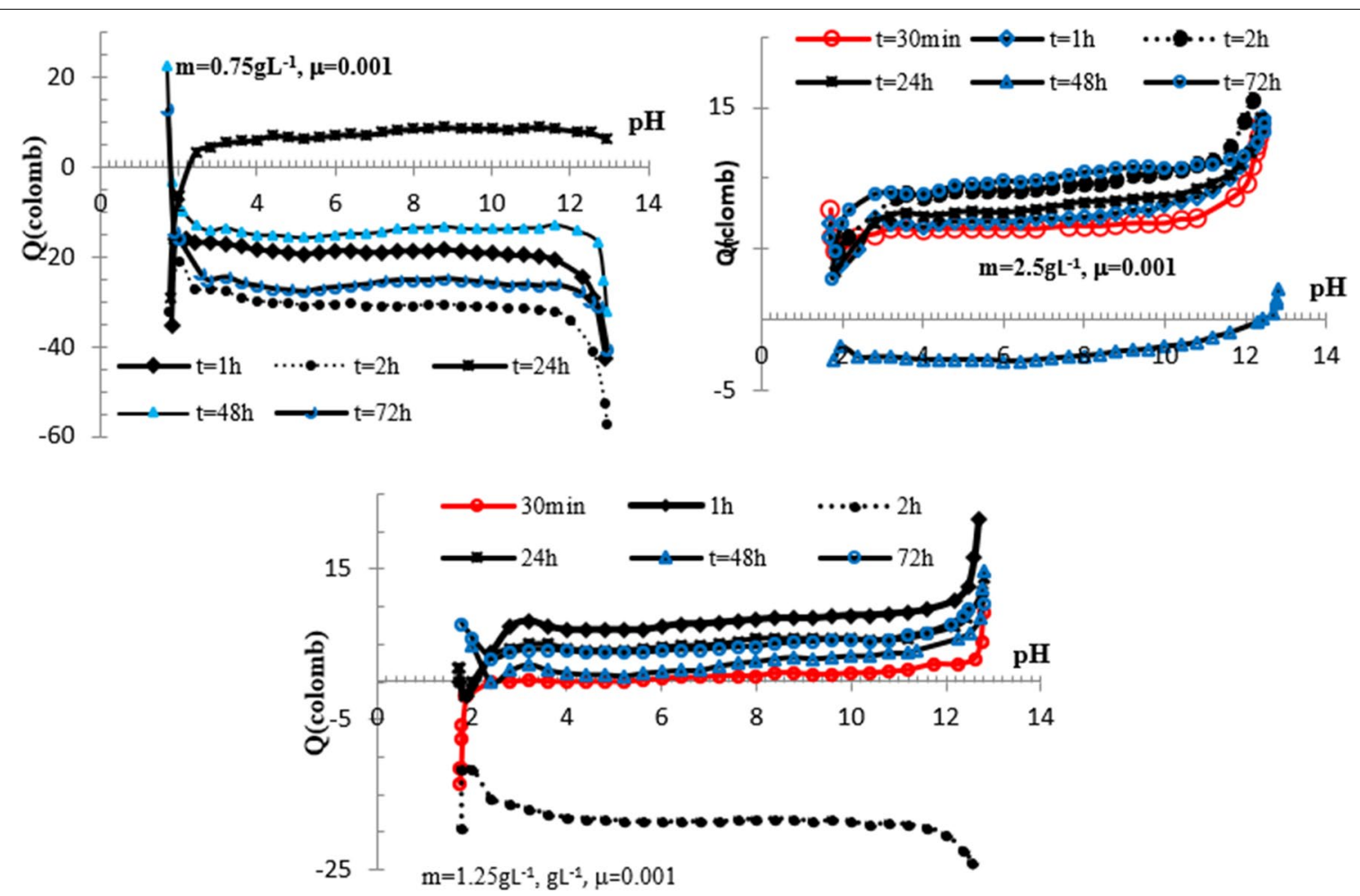

Fig. 6 Variations $\mathrm{Q}$ in function of $\mathrm{pH}$ obtained for $\mathrm{Fe}_{2}\left(\mathrm{HPO}_{4}\right)_{3}{ }^{*} 4 \mathrm{H}_{2} \mathrm{O}$ in $\mathrm{NaCl} 0.001 \mathrm{M}$ and m=0.75, 1.25, $2.5 \mathrm{~g} \mathrm{~L}^{-1}, 0.5 \mathrm{~h} \leq T \leq 72 \mathrm{~h}$ 

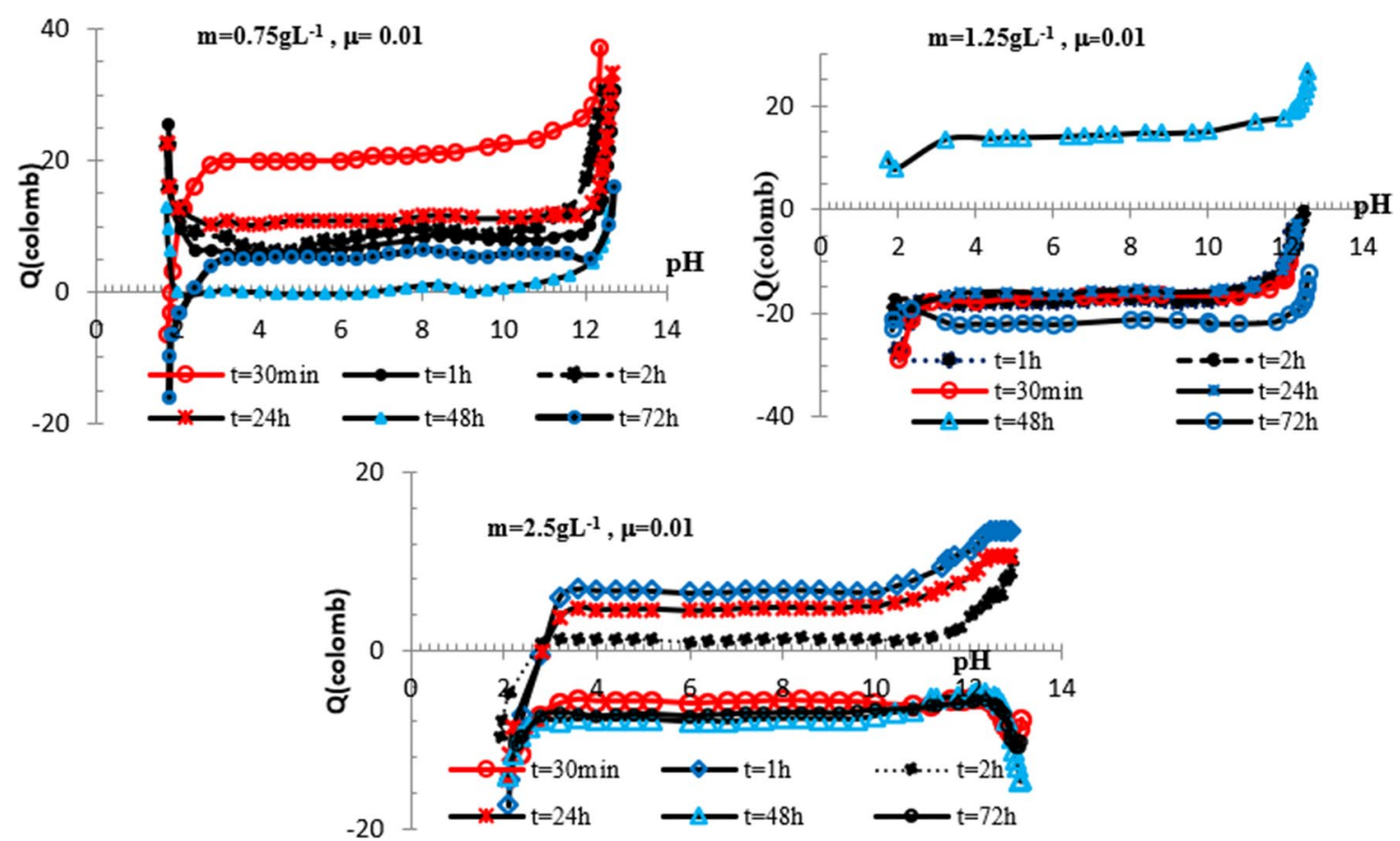

Fig. 7 Variations $\mathrm{Q}$ in function of $\mathrm{pH}$ obtained for $\mathrm{Fe}_{2}\left(\mathrm{HPO}_{4}\right)_{3}{ }^{*} 4 \mathrm{H}_{2} \mathrm{O}$ in $\mathrm{NaCl} 0.01 \mathrm{M}$ and $\mathrm{m}=0.75,1.25$ and $2.5 \mathrm{~g} \mathrm{~L}-1,0.5 \mathrm{~h} \leq T \leq 72 \mathrm{~h}$
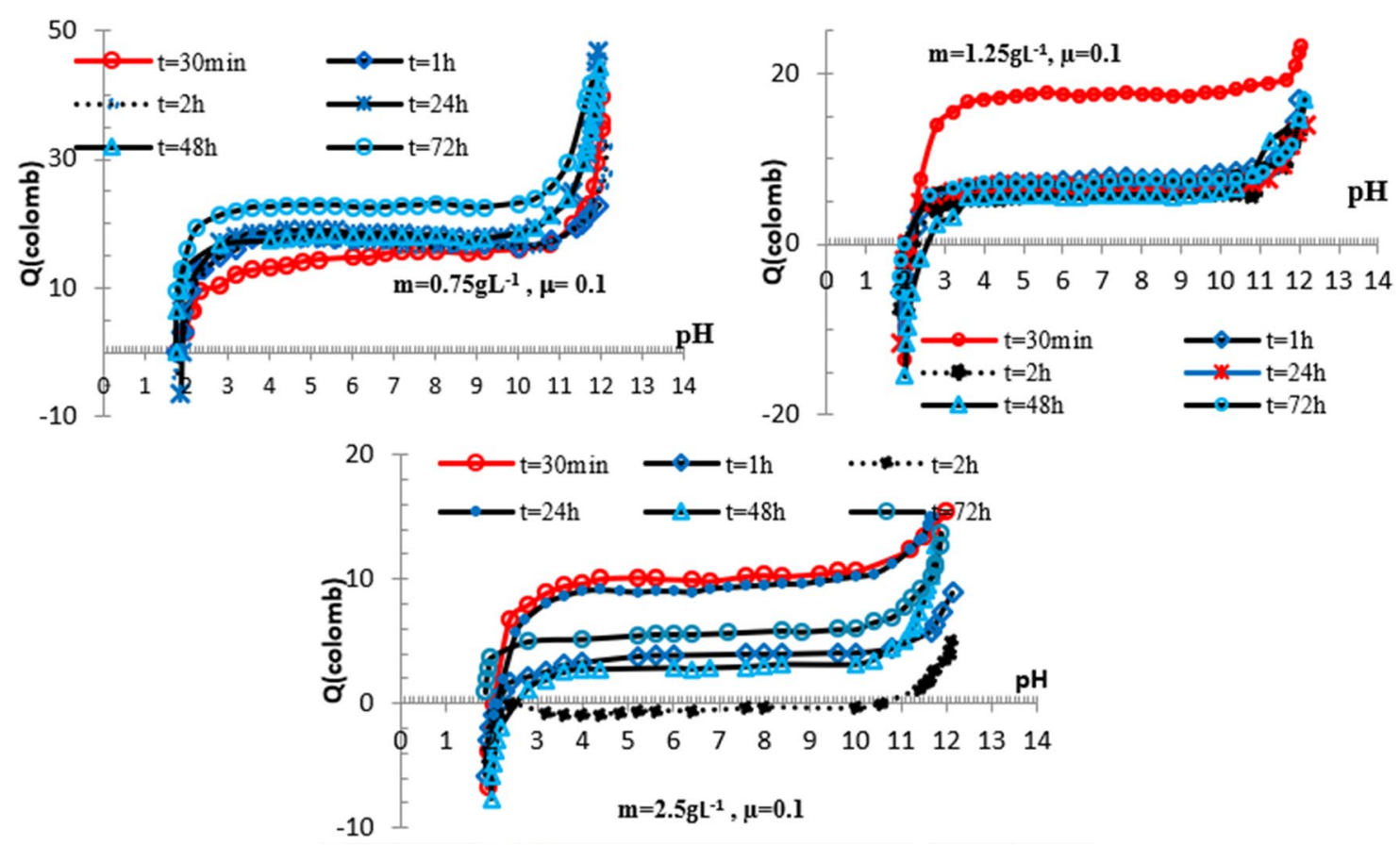

Fig. 8 Variations $\mathrm{Q}$ in function of $\mathrm{pH}$ obtained at $\mathrm{Fe}_{2}\left(\mathrm{HPO}_{4}\right)_{3}{ }^{*} 4 \mathrm{H}_{2} \mathrm{O}$ in $\mathrm{NaCl} 0.1 \mathrm{M}$ and $\mathrm{m}=0.75,1.25$ and $2.5 \mathrm{~g} \mathrm{~L}^{-1}, 0.5 \mathrm{~h} \leq T \leq 72 \mathrm{~h}$ 
important to note that the isoelectric point is comparable to $\mathrm{PZC}$ value of $\overline{\mathrm{POH}}[28,31]$.

\section{Surface complexation constant}

The surface complexations involved in protonation/ deprotonation reactions are dependent on suspension acidity. As shown previously, the strength of surface functional groups are altered, due to inter- and intramolecular interactions. Consequently, it is assumed that each definite set of individual $>\mathrm{SOH}$ group is characterized by distinct acidity constants $\left(\mathrm{K}_{\mathrm{a}}\right)$ [32].

This result achieved at contact time of $24 \mathrm{~h}$, is suggested to be due to the complexity and heterogeneity of sorbent surface. However, it is shown previously that sorption is more complexed kinetic phenomenon witch optimal conditions are not always corresponding to higher duration [5].

The results of potentiometric titrations carried out at various contact times show that the phosphate systems are characterized by comparable acidity constants, $\mathrm{K}_{\mathrm{a}}$, that $\mathrm{pK}_{\mathrm{a}}$ value is equal to $2.4 \pm 0.2$. One can note that this $\mathrm{pK}_{\mathrm{a}}$ is equal to $\mathrm{PZC}$ of $\overline{>\mathrm{POH}}$ group which ionization seems to be rather correlated to the contact time than to nature of this surface acid group.

Taking this result into account, the surface charge behavior of synthesized $\mathrm{Fe}_{2}\left(\mathrm{HPO}_{4}\right)_{3} * 4 \mathrm{H}_{2} \mathrm{O}$ is dominated by the phosphohydrols $\overline{>\mathrm{POH}}$ which deprotonation reactions are prevailing under acidic conditions. The acidic sites are deprotonated following the reaction:

$$
\overline{>\mathrm{P}\left(\mathrm{OH}_{2}\right)^{+}} \leftrightarrow \overline{>\mathrm{POH}}+\mathrm{H}^{+}, \mathrm{pK}_{\mathrm{a}}
$$

The experimental results show that $\mathrm{pKa}=2.45 \pm$ 0.15 .

The partition equilibrium involving sodium ion insertion is:

$$
\begin{aligned}
& \overline{>\mathrm{P}\left(\mathrm{OH}_{2}\right)^{+}}+\mathrm{Na}^{+} \leftrightarrow \overline{>\mathrm{P}\left(\mathrm{OH}_{2}^{+}, \mathrm{Na}^{+}\right)}, \\
& \mathrm{K}_{\mathrm{Na}} \approx \frac{Q}{96500 \overline{\left[>\mathrm{SOH}_{2}^{+}\right]}\left[\mathrm{Na}^{+}\right]_{0}}
\end{aligned}
$$

The overall surface complexation reaction is:

$$
\begin{aligned}
& \overline{\mathrm{POH}}+\mathrm{H}^{+}+\mathrm{Na}^{+} \leftrightarrow \overline{>\mathrm{P}\left(\mathrm{OH}_{2}^{+}, \mathrm{Na}^{+}\right)}, \\
& \mathrm{K}_{>\mathrm{SOH}} \approx \frac{\mathrm{K}_{\mathrm{Na}}}{\mathrm{K}_{\mathrm{a}}}
\end{aligned}
$$

Under optimal conditions corresponding to suspension of $0.75 \mathrm{~g} \mathrm{~L}^{-1}(0.067 \mathrm{M}), \mu=0.1$ and $\mathrm{pH}$ about 1.8, Q and $\overline{\left[>\mathrm{SOH}_{2}^{+}\right]}$are found to be equal respectively to $20 \mathrm{C}$ and $0.007 \mathrm{M}$. As a consequence log $\mathrm{K}_{\mathrm{Na}}=-0.68 \pm 0.02$ and $\log \mathrm{K}_{>\mathrm{SOH}}=1.77 \pm 0.27$.

\section{Response surface analysis}

The mathematical models for the for the sodium insertion in amorphous Iron Phosphate and dyes removal were used to build response surfaces as well as to determine the optimal conditions of the process. Figure 9 present the $3 \mathrm{D}$ response surfaces plots for the significant interactions.

The mathematical models for the sodium number were used to build response surfaces as well as to determine the optimal conditions of the process. Figure 9 presents the $3 \mathrm{D}$ response surfaces plots for the significant interactions.

For the sodium insertion number, the most significant interactions were the time, $\mathrm{pH}$ and Q. Figure $9(\mathrm{~m}=0.75 \mathrm{~g} / \mathrm{l})$ indicates that the sodium number increased with the increase of activation $\mathrm{pH}, \mathrm{Q}$ and $\mathrm{m}$ ratio. Figure $9(\mathrm{~m}=1.25 \mathrm{~g} / \mathrm{l})$ shows that the sodium insertion in amorphous Iron Phosphate increased with increase of the impregnation ratio and decrease of activation time when the activation time is fixed at $30 \mathrm{~min}$.

For the $\mathrm{t}=30 \mathrm{~min}$ and $72 \mathrm{~h}, \mathrm{~m}=0.75 \mathrm{~g} / \mathrm{l}$ index, the most significant interaction was the $\mathrm{Q}$ and activation pH. From Fig. $9(\mathrm{~m}=1.25 \mathrm{~g} / \mathrm{l})$, it can be observed that the Sodium index increased with the increase of the activation $\mathrm{Q}$ and the $\mathrm{pH}$. The maximal sodium index response was obtained at an activation time of $72 \mathrm{~h}$.

For the $\mathrm{t}=30 \mathrm{~min}$ and $72 \mathrm{~h}, \mathrm{~m}=1,25 \mathrm{~g} / \mathrm{l}$ index, in the insertion of sodium, the same significant interactions are found, including the $\mathrm{Q}$ and $\mathrm{pH}$. From Fig. $9(\mathrm{~m}=2.5 \mathrm{~g} / \mathrm{l})$, it can be observed that the sodium insertion increased with increase of the activation time and Q. The maximal sodium responses were obtained at an activation time of $30 \mathrm{~min}$. Figure $9(\mathrm{~m}=2.5 \mathrm{~g} / \mathrm{l})$ shows that the sodium increased with decrease $\mathrm{Q}$ and decreased activation time in case the activation time is fixed at $72 \mathrm{~h}$.

For the $\mathrm{t}=30 \mathrm{~min}$ and $72 \mathrm{~h}, \mathrm{~m}=2,5 \mathrm{~g} / \mathrm{l}$ index, the most significant interaction was the $\mathrm{Q}$ and activation $\mathrm{pH}$. From Fig. $9(\mathrm{~m}=1.25 \mathrm{~g} / \mathrm{l})$, it can be observed that the Sodium index increased with the increase of the activation $Q$ and the $\mathrm{pH}$. The maximal sodium index response was obtained at an activation time of $72 \mathrm{~h}$.

\section{Conclusion}

In the present study, the synthesis of iron (III) hydrogen phosphate is performed using inorganic sol-gel method coupled to microwave irradiation. The surface chemistry of obtained phosphate is performed using Kinetic-potentiometric method (KPM) which is a derived from the Potentiometric Mass Titrations (PMT) and 


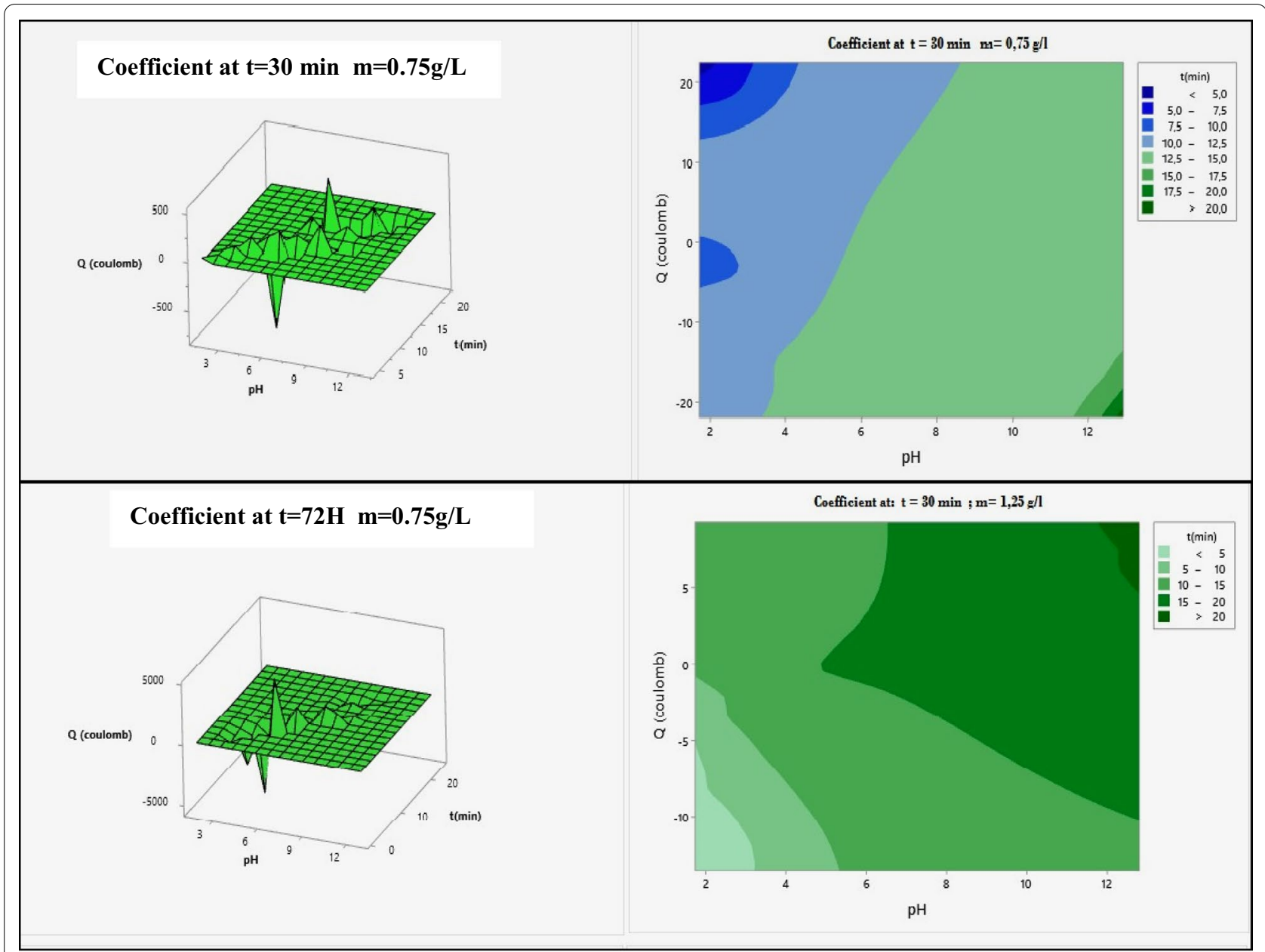

Coefficient at $\mathrm{t}=30 \mathrm{~min} \mathbf{m}=1.25 \mathrm{~g} / \mathrm{L}$

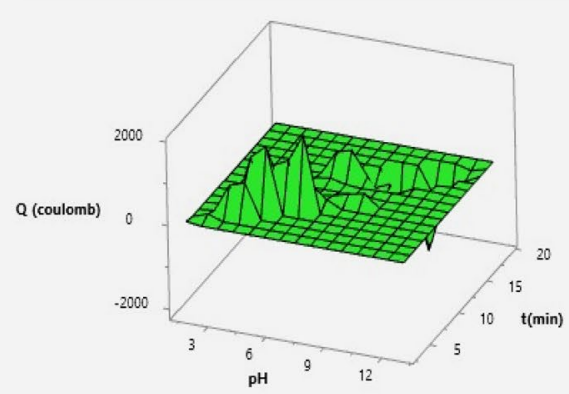

Coefficient at $\mathrm{t}=72 \mathrm{~h} \quad \mathrm{~m}=0,75 \mathrm{~g} / \mathrm{l}$

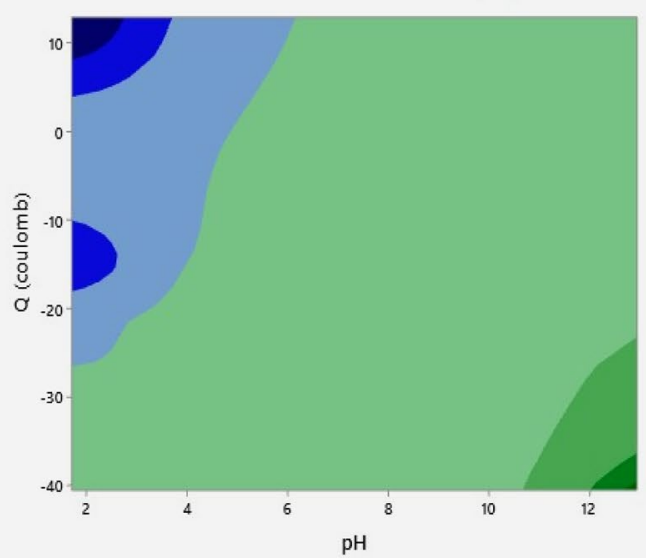

- $\stackrel{t(\min )}{<} 5,0$ $5.0-7.5$ $10,0-12,5$
$10.5-150$ $70,0-12,5$
$12,5-15,0$ $15,0-17,5$ - > 17,5

$\mathrm{pH}$

Fig. 9 Surface response plots for the sodium insertion in amorphous Iron Phosphate for $\mathrm{m}=0.75,1.25$ and $2.5 \mathrm{~g} \mathrm{~L}^{-}$

Potentiometric Time Titrations (PTT) methods. The $\mathrm{pH}$ of common intersection of $\frac{\mathrm{dpH}}{d T}$ in function of $\mathrm{pH}$ curves corresponds to PZC and IEP values that are found to be 4.3. Obtained results are used to evaluate the influence of synthesis conditions on the surface chemistry of the $\mathrm{Fe}_{2}\left(\mathrm{HPO}_{4}\right)_{3}{ }^{*} 4 \mathrm{H}_{2} \mathrm{O}$. For these purpose, phosphate 

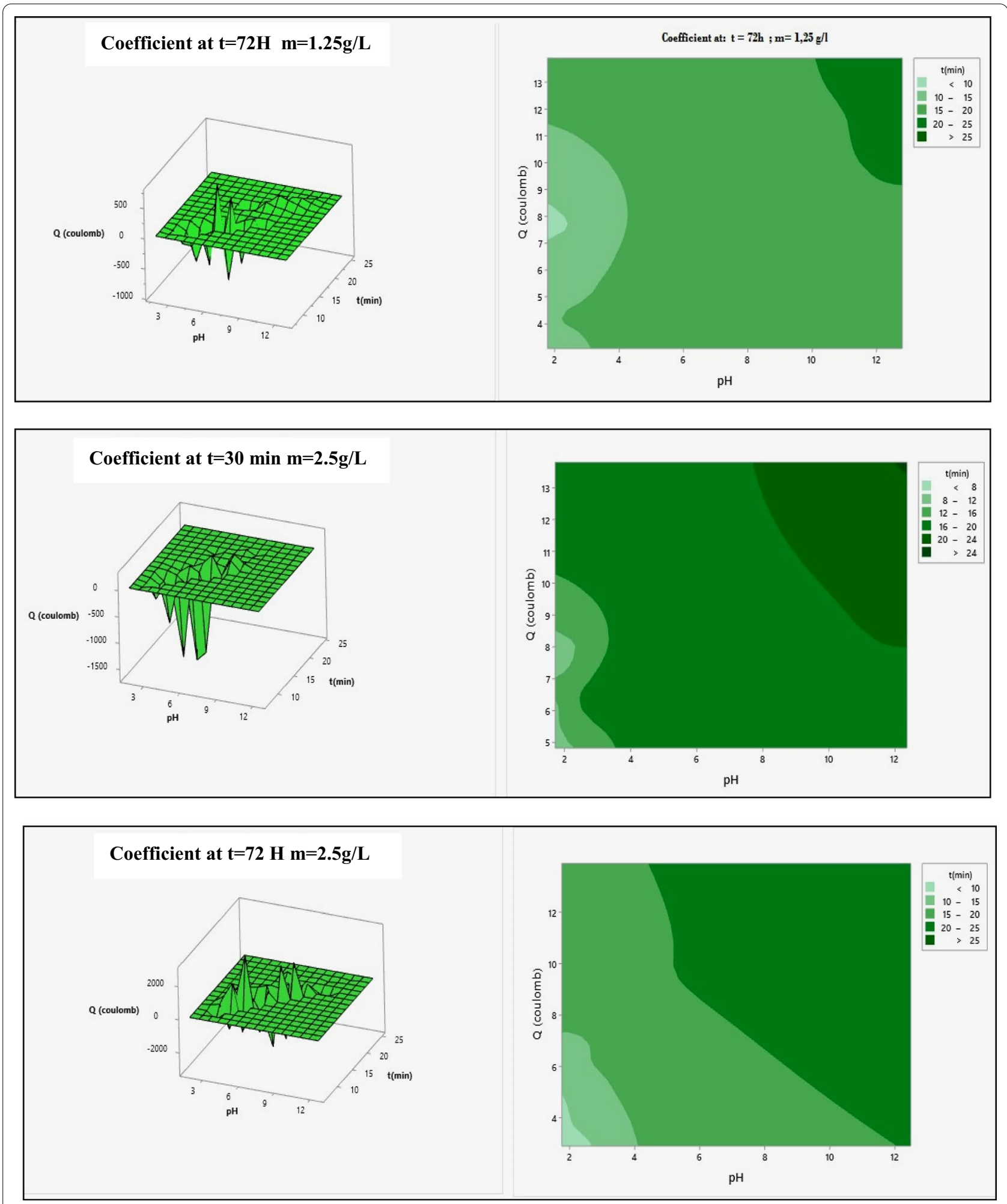

Fig. 9 continued 

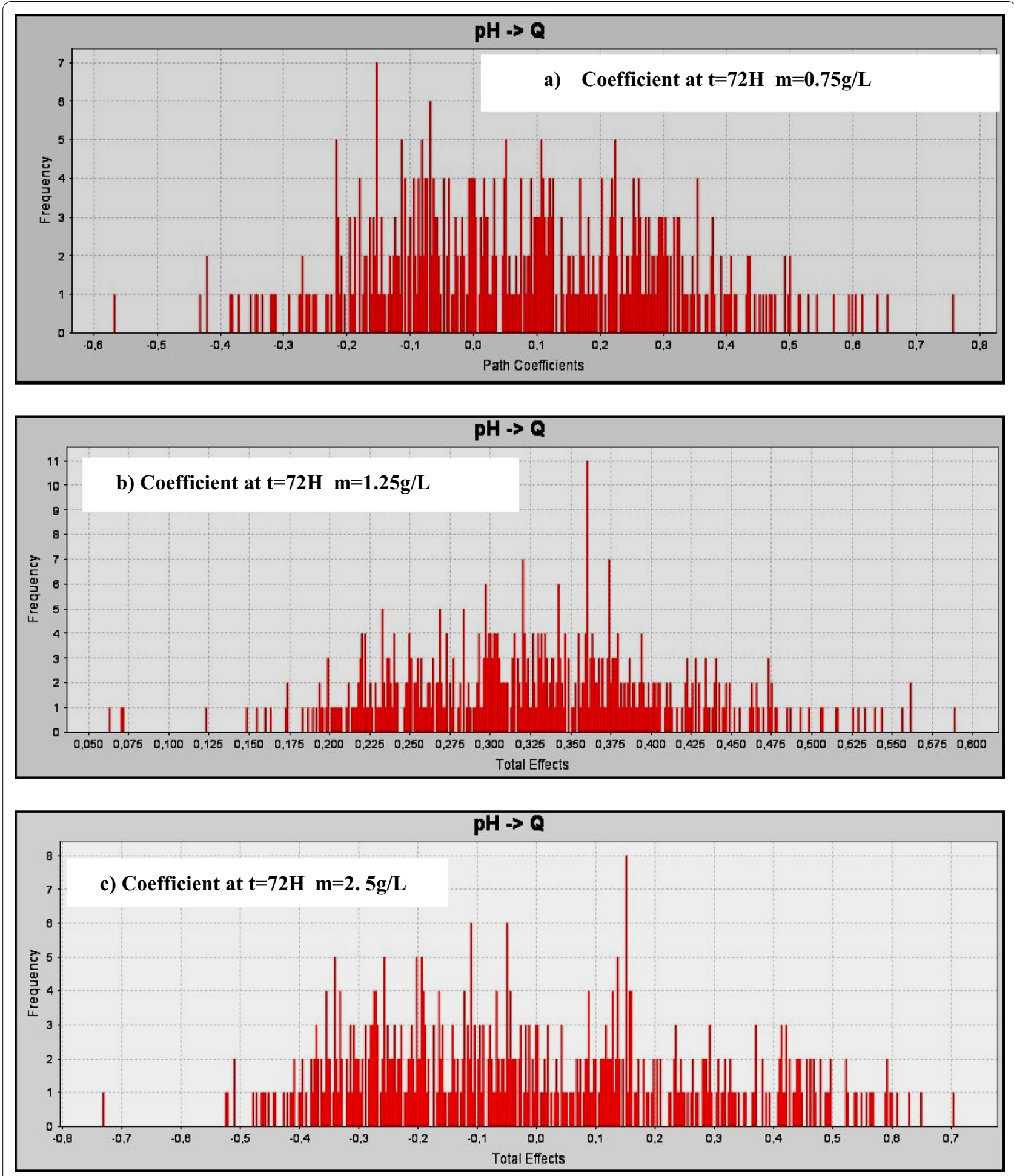

Fig. 9 continued

surface charge is studied at different ionic strength. The positive variable charge which is $\mathrm{pH}$-independent is due to the accumulation of sodium ion in the material surface, mainly achieved by insertion process. The maximal surface charge (Q) is achieved at the low solid suspension. Hence, for $\mathrm{m}=0.75 \mathrm{~g} \mathrm{~L}^{-1}$, $\mathrm{Q}$ value of 50 coulombs is carried at $\mu=0.1$ and $\mathrm{pH}$ around 12 , while charge value around 22 coulombs is reached in the $\mathrm{pH}$ range: 
3-10. These results are in agreement with those obtained previously indicating that the alkali ion diffusion in low suspensions medium is much faster than that in bulk. A shift is observed for PZC and IEP towards low values that are found to be $2.2 \pm 0.2$ and $1.8 \pm 0.1$, respectively. In acidic conditions, the surface charge behavior of synthesized phosphate is dominated by $>\mathrm{POH}$ group which $\mathrm{pKa}=2.45 \pm 0.15$. The equilibrium constant of sodium ion insertion is found to be $\log \mathrm{KNa}=-0.68 \pm 0.02$, while the overall surface complexation constant is $\log \mathrm{K}>\mathrm{SOH}=1.77 \pm 0.27$.

\section{Abbreviations}

PTT: Potentiometric Time Titration; PMT: Potentiometric Mass Titration; PZC: Point of zero charge; IEP: Isoelectric point; TGA: Thermogravimetric analysis; SEM: Scanning Electron Microscope; DTA: Differential thermal analysis.

\section{Acknowledgements}

The authors would like to thank both department of chemistry at An-Najah National University in Palestine and Mohammed Premier University in Oujda, Morocco.

\section{Authors' contributions}

FM, SS and KA designed and performed the research. CC and HK analyzed the data, interpreted the results and prepared the manuscript. SE and SL performed the assay, conducted the optimization, purifcation of compounds. $\mathrm{OB}, \mathrm{BH}$ and $\mathrm{SJ}$ revised the manuscript. All authors read and approved the fnal manuscript.

\section{Funding}

There is no funding to show in this manuscript.

\section{Availability of data and materials}

All data generated or analysed during this study are included in this published article.

\section{Declarations}

Ethics approval and consent to participate

Not applicable.

\section{Consent for publication}

Not applicable.

\section{Competing interests}

We declare that all authors do no competing interest.

\begin{abstract}
Author details
${ }^{1}$ Laboratoire de Chimie Appliquée Des Matériaux (LCAM), Faculty of Sciences, Mohammed V University, Rabat, Morocco. ${ }^{2}$ LCAE-URAC18, COST, Department of Chemistry, Faculty of Sciences, Mohamed 1st University, P.O. Box 717, 60000 Oujda, Morocco. ${ }^{3}$ Management and IS Research Group - National School of Business \& Management, Abdelmalek Essaadi University, Tangier, Morocco. ${ }^{4}$ Department of Chemistry, College of Science, An-Najah National University, Nablus, Palestine. ${ }^{5}$ Department of Management, Laayoune Higher School of Technology, Ibn Zohr University, Agadir, Morocco.
\end{abstract}

Received: 3 February 2021 Accepted: 2 August 2021

Published online: 17 August 2021

\section{References}

1. Kuz S, Kageura J, Matsumoto S, Nakayama T, Makidera M, Saka M, Yamaguchi T, Yamamoto T, Nakane K. Development of a sodium ion secondary battery. Sumimoto Kagarku. 2013;2013:1-13.

2. Hwang J-Y, Myung S-T, Sun Y-K. Sodium-ion batteries: present and future. Chem Soc Rev. 2017;46:3529.

3. Mathew V, Kim S, Kang J, Gim J, Song J, Baboo JP, Park W, Ahn D, Han J, Gu L, Wang Y, Hu Y-S, Sunn Y-K, Kim J. Amorphous iron phosphate: potential host forvarious charge carrier ions. NPG Asia Mater. 2015;7:e149.

4. Bonilla MR, Lozano A, Escribano B, Carrasco J, Akhmatskay E. Revealing the mechanism of sodium diffusion in NaxFePO4 using an improved force field. J Phys Chem C. 2018;122(15):8065-75.

5. Yu F, Zhang L, Li Y, An Y, Zhu M, Dai B. Mechanism studies of LiFePO4 cathode material: lithiation/delithiation process, electrochemical modification and synthetic reaction. Royal Soc Chem Adv. 2014;4(97):54576-602.

6. Kim J, Seo D-H, Kim H, Park I, Yoo J-K, Jung S-K, Park Y-U, Goddard WA III, Kang K. Unexpected discovery of low-cost maricite $\mathrm{NaFePO}_{4}$ as a high-performance electrode for $\mathrm{Na}$-ion batteries. Energy Environ Sci. 2015;8:540-5

7. Galceran M, Saurel D, Acebedo B, Roddatis V, Martin E, Rojoa T, CasasCabanas M. The mechanism of NaFePO4 (de)sodiation determined by in situ X-ray diffraction. Phys Chem Chem Phys. 2014;16:8837-42.

8. Gulicovski JJ, Ćerović LS, Milonjić SK. Point of zero charge and isoelectric point of alumina. Mater Manuf Processes. 2008;23:615-9.

9. Venema P. Charging and ion adsorption behaviour of different iron (hydr) oxides. Wageningen: Ph.D. thesis, Wageningen Agricultural University; 1997.

10. Fiol N, Villaescusa I. Determination of sorbent point zero charge: usefulness in sorption studies. Environ Chem Lett. 2009;7:79-84.

11. Elyahyaoui A, Bouhlassa $S$, Maatallah I. Crystals of new ferric acid phosphate, $\mathrm{Fe}_{3} \mathrm{H}_{3}\left(\mathrm{PO}_{4}\right)_{4} \cdot 6 \mathrm{H}_{2} \mathrm{O}$, performed by inorganic sol-gel process. J Incl Phenom Macrocycl Chem. 2002;43:101-6.

12. Babas H, Kaichouh G, Khachani M, Karbane ME, Chakir A, Guenbour A, Bellaouchou A, Warad I, Zarrouk A. Equilibrium and kinetic studies for removal of antiviral sofosbuvir from aqueous solution by adsorption on expanded perlite: Experimental, modelling and optimization. Surf Interfaces. 2021;23:100962.

13. Frost RL, Martens W, Williams PA, Kloprogge JT. Raman and infrared spectroscopic study of the vivianite-group phosphates vivianite, baricite and bobierrite. Mineralogical Magazine. 2002;66(6):1063-73.

14. Palacios E, Leret P, Fernández JF, De Aza AH, Rodríguez MA. Synthesis of amorphous acid iron phosphate nanoparticles. J Nanoparticle Res. 2012;14:1131.

15. Frost RL, Xi Y, Scholz R, López A, Belotti FM. Vibrational spectroscopic characterization of the phosphate mineral hureaulite - ( $\mathrm{Mn}$, $\mathrm{Fe})_{5}\left(\mathrm{PO}_{4}\right)_{2}\left(\mathrm{HPO}_{4}\right)_{2} \cdot 4\left(\mathrm{H}_{2} \mathrm{O}\right)$. Vibrat Spectrosc. 2013;66:69-75.

16. Michelot A, Sard S, Audin C, Deydier E, Manoury E, Poli R, Rey C. Spectroscopic characterisation of hydroxyapatite and nanocrystalline apatite with grafted aminopropyltriethoxysilane: nature of silane-surface interaction. J Mater Sci. 2015;50(17):5746-575.

17. Zhu Y, Ruan Z, Tang S, Thangadurai V. Research status in preparation of $\mathrm{FePO}_{4}$ :a review. lonics. 2014;20:1501-10.

18. Gongyan W, Li L, Fang $\mathrm{H}$. Dehydration of FePO ${ }_{4} \cdot 2 \mathrm{H}_{2} \mathrm{O}$ for the synthesis of $\mathrm{LiFePO}_{4} / \mathrm{C}$ : effect of dehydration temperature. Int J Electrochem Sci. 2018;13:2498-508.

19. Saritha D, Bose PSC, Reddy PS, Madhuri G, Nagaraju R. Improved dissolution and micromeritic properties of naproxen from spherical agglomerates: preparation, in vitro and in vivo characterization. Braz J Pharm Sci. 2012;48(4):667-76.

20. Liu Y, Xu Y, Han X, Pellegrinelli C, Zhu Y, Zhu H, Wan J, Chung AC, Vaaland O, Wang C, Hu L. Porous amorphous FePO4 nanoparticles connected by single-wall carbon nanotubes for sodium ion battery cathodes. Nano Lett. 2012;12:5664-8.

21. Sfaelou S, Vakros J, Manariotis ID, Karapanagioti HK. The use of potentiometric mass titration (PMT) technique for determining the acid-base behavior of activated sluge. Global NEST J. 2015;17(2):397-405.

22. Mustafa S, Murtaza S, Naeem A, Dilara B, Farina K. Cation-exchange properties of $\mathrm{CrPO}_{4}$. Adsorpt Sci Technol. 2003;21(2):149-60.

23. Luna-Zaragoza D, Romero-Guzmán ET, Reyes-Gutiérrez LR. Surface and physicochemical characterization of phosphates vivianite, 
$\mathrm{Fe}_{2}\left(\mathrm{PO}_{4}\right)_{3}$ and hydroxyapatite, $\mathrm{Ca}_{5}\left(\mathrm{PO}_{4}\right)_{3} \mathrm{OH}$. J Miner Mater Charact Eng. 2009;8(8):591-609.

24. Zhang W, Honaker R. Surface charge of rare earth phosphate (monazite) in aqueous solutions. Powder Technol. 2017;318:263-71.

25. Cardenas-Peña AM, Ibanez JG, Vasquez-Medrano R. Determination of the point of zero charge for electrocoagulation precipitates from an iron anode. Int J Electrochem Sci. 2012;7:6142-53.

26. Hofmann AF, Middelburg JJ, Meysman FJR, Greenwood J. The effect of biogeochemical processes on pH Karline Soetaert. Marine Chem. 2007;105:30-51.

27. Zuccaro L, Krieg J, Desideri A, Kern K, Balasubramanian T. the isoelectric point of graphene by electrochemical functionalization. Sci Rep. 2015;5:11794. https://doi.org/10.1038/srep11794.

28. De Tommaso G, Iuliano M. Aciod-base properties of the surface of hydrous ferric phosphate in aqueous solutions. J Chem Eng Data. 2012;57(1):52-9.

29. Campos AFC, de Medeiros WC, Aquino R, Depeyrot J. Surface charge density determination in water based magnetic colloids: a comparative study. Mater Res. 2017;20(6):1729-34.
30. Campos AFC, Aquino R, Tourinho FA, Paula FL, Depeyrot J. Influence of the spatial confinement at nanoscale on the structural surface charging in magnetic nanocolloids. Eur Phys J E. 2013;36(4):9856.

31. Barkauskas J, Marytedervinyte D. An investigation of the functional groups on the surface of activated carbons. J Serb Chem Soc. 2004;69(5):363-75.

32. Elyahyaoui A, Ellouzi K, Al Zabadi H, Razzouki B, Bouhlassa S, Azzaoui K, Mejdoubi EM, Hamed O, Jodeh S, Lamhamdi A. Adsorption of chromium (VI) on calcium phosphate: mechanisms and stability constants of surface complexes. Appl Sci. 2017;7(3):222.

\section{Publisher's Note}

Springer Nature remains neutral with regard to jurisdictional claims in published maps and institutional affiliations.
Ready to submit your research? Choose BMC and benefit from:

- fast, convenient online submission

- thorough peer review by experienced researchers in your field

- rapid publication on acceptance

- support for research data, including large and complex data types

- gold Open Access which fosters wider collaboration and increased citations

- maximum visibility for your research: over 100M website views per year

At BMC, research is always in progress.

Learn more biomedcentral.com/submissions 